\title{
Investigation and Analysis on the Present Situation of Children's Latin Dance Training in Pingxiang City
}

\author{
Huirong $\mathrm{Xu}$ \\ College of Physical Education \\ Yan'an University \\ Yan'an, China 716000
}

\begin{abstract}
In recent years, there has been a fiery wind in our country, and now it has entered the Asian games. With the popularity of sports dance, Latin dance training institutions in Pingxiang have mushroomed, and the training institutions for Latin dance can be seen everywhere, whether in the main cities or towns. Aiming at some problems appeared in the development of children's Latin dance training institutions in Pingxiang and summarized through the data collection and data analysis, put forward some opinions and suggestions, and provide targeted measures for the development of Pingxiang children's Latin dance.
\end{abstract}

Keywords-Pingxiang city; children' slatin dance; teaching; the statusquo; countermeasures

\section{INTRODUCTION}

Latin dance originated from Latin America and is one of the most beautiful dances in the world. It is composed of five dance types, including rumba, cha and bullfight, which blend into music, dance, costume and body. Latin dance is a sport that has its own entertainment and competitive performances. It is loved by people because of its unique charm. In today's society parents began to attach importance to the all-round development of children, especially in the children's art education, dance art has become one of the first, in the dance selection, many parents for Latin dance unique skills and it produces. Therefore, in this view of many parents, the youth Latin dance team is gradually growing in our country. Since 1994, China has held a competition program for children's sports dance, and the number of participants has been thriving in recent years, especially the Latin dance market. In recent years, we have also had a hot wind in our country, and now we have entered the Asian games. With the popularity of sports dance, the Latin dance training institutions have mushroomed in Pingxiang city, whether in the main city or the township, the Latin dance training institution can be seen everywhere. But as these training institutions grew, so did the conflict. At present, in the course of the process, there are a disproportionate number of female students, and the number of female students is far higher than that of the male students. In the course of learning, there are few opportunities for the couple to dance with each other, and there is an imbalance. The learner's motivation is not obvious; the teaching methods and technical training level of the coaches need to be improved and improved. A series of related problems, such as the lack of facilities to meet standard conditions, hinder the progress of the young Latin dance in Pingxiang city. In this paper, the current situation of children Latin dance training in Pingxiang city is studied and analyzed from the aspects of trainees, teachers, teaching methods, venue facilities and training management. Find out the factors restricting the development of Pingxiang children's Latin dance training institutions, explore the rules of the development of Pingxiang children's Latin dance training institutions suitable for the development of the recommendations and measures targeted strategy to promote the better development of the training market for children Latin dance in Pingxiang city.

\section{RESEARCH OBJECT AND METHOD}

\section{A. Research Objects}

Pingxiang children's Latin dance training is taken to carry out the status quo as the research object, Pingxiang to art school, health and beauty, interpret dream art school, little rose buds art school art school 15 coaches in the four training institutions and students as the object of investigation of 150 children.

\section{B. Research Methods}

1) Literature method: According to the research needs, some theoretical basis is obtained through the analysis and exploration of the literature books of "the development of children Latin dance" through China zhi.com.

2) Questionnaire survey method: To Pingxiang children's Latin dance training institution with the method of questionnaire research, draw art school, health and beauty, a dream school of art, small rose buds art school art school of the four institutions for training of trainers and trainees parents questionnaire.

A total of 165 questionnaires were issued and 160 were recovered.

Among them, the coach questionnaires 15 copies, recycling 15 copies, the recovery rate is $100 \%$.

In this paper, 150 questionnaires were distributed to students, 145 copies were collected, $96.67 \%$ of the recovery rate was recovered, 139 effective questionnaires were 
collected, effective recovery rate was $92.67 \%$, and all the results were systematically studied.

3) Interviews: Pingxiang through the school of art, health and beauty, a dream school of art, small rose buds art school art school of the four interview head coaches and training institutions, to understand the current situation of Pingxiang Latin dance training, seek development Suggestions.

4) Mathematical statistics: The data obtained from the survey were carried out with Excel 2007 software, and statistical charts were made.

\section{RESULTS AND ANALYSIS}

\section{A. Basic Situation of Junior Latin Dancers in Pingxiang City}

1) The cognitive situation of Latin dance students for Latin dance: The young Latin dance students are mostly between the ages of 4 and 14, and the cognitive level of Latin dance is basic level, just to stay in the literal sense, and not deep enough.

In Latin dance, the majority of students are parents' choice, and their understanding and liking of Latin dance is not so strong, which is a compulsive type.

Students' liking for Latin dance has a direct impact on the degree of learning and learning atmosphere of Latin dance, and the students' initiative learning is very important in the process of learning.

2) Analysis of learning motivation of children Latin dance: Learning motivation surveys of Pingxiang children's Latin dance, we can learn according to the choice of the parents to learn to dance of many students and only small part of students like and learn.

The survey data shows that most of the parents of students learning Latin dance to realize by dancing to shape the form and the cultivation of interest in art is a majority, the data analysis requirements Pingxiang children's Latin dance training mode diversification to increase children's interest in Latin dance training, Pingxiang efforts to improve children's Latin dance teaching model standardization as in "Table I".

TABLE I. QUESTIONNAIRE OF LEARNING MOTIVATION OF JUNIOR LATIN DANCE IN PINGXIANG CITY $(\mathrm{N}=139)$

\begin{tabular}{llll}
\hline Percentage of study & Motivation & Percentage (\%) & sort \\
\hline Art cultivation & 123 & $88.49 \%$ & 1 \\
Shape the body & 116 & $83.45 \%$ & 2 \\
The parents asked & 99 & $71.22 \%$ & 3 \\
I like & 65 & $46.76 \%$ & 4 \\
Other & 34 & $24.46 \%$ & 5 \\
\hline
\end{tabular}

3) Analysis of age and sex ratio of junior Latin dancers

"Table II" shows that there are more female students in the junior Latin dance in Pingxiang city than male students and the age period is mainly between the ages of 7 and 12 , and the number of participants in other ages is lower.

The majority of girls in Pingxiang children's Latin dance cadets show that there is a large imbalance between men and women.

Because with Latin dance is the need for men and women in the dance, in normal cases, the proportion of $1: 1$ is required, but most of the training institutions to learn Latin dance too little boys, and even some institutions are not the boy students.

This can lead to a low interest in dance, because dance partners are an important factor in learning Latin dance.

According to the questionnaire, it can be seen that the children of young Latin dancers in Pingxiang city are aged between 4 and 6 , with 24 percent, 7 to 9 years old and 34 percent, from 10 to 12 years, and 13 percent from 13 to 14 years old.

Student age in primary school in the majority, for children at this stage is in the midst of the autonomous learning ability and understanding ability is poor and when the coach taught the basic action cannot be fully achieved.

But learning to imitate is strong, the ability to be curious about things and to accept new things will be prominent, it is a good time to learn Latin dance.

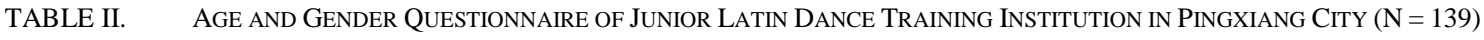

\begin{tabular}{llllll}
\hline \multicolumn{2}{c}{ Age structure } & \multicolumn{3}{c}{ gender structure } \\
\hline Age & The number of & Percentage (\%) & gender & The number of & Percentage $(\%)$ \\
$4-6$ & 33 & $24 \%$ & men & 21 & $15 \%$ \\
$7-9$ & 47 & $34 \%$ & female & 118 & $85 \%$ \\
$10-12$ & 41 & $29 \%$ & --- & --- & --- \\
$13-14$ & 18 & $13 \%$ & --- & --- & --- \\
A total of & 139 & 100.00 & --- & 139 & 100.00 \\
\hline
\end{tabular}

4) Training time and teaching sub-class situation: The junior Latin dance training institute generally divided the training class into first class, intermediate class and advanced class.

The training of Latin dance is usually based on the basic level, learning time and age of the students.

It can be seen from "Table III" that the training institution is focused on the two-day two-day weekend and the training

time is between 1.5 and 2 hours. Only the advanced class lasts 2-3 hours.

Latin dance is an endurance, need long-term basic footwork training and physical training, the combination of Latin dance beginner class and intermediate class contact time is not long and learn dance or is relatively single, so the training time relative to the advanced training time will be shorter. 
In the higher class, students are more receptive and selfmotivated, and the dancers are more physically active than those in junior and intermediate classes, so the class time is longer.

TABLE III. TRAINING TIME OF JUNIOR LATIN DANCE TRAINING INSTITUTION IN PINGXIANG CITY

\begin{tabular}{lllll}
\hline & junior & \multicolumn{1}{c}{$\begin{array}{c}\text { The intermediate } \\
\text { class }\end{array}$} & \multicolumn{2}{c}{ advanced } \\
\hline $\begin{array}{l}\text { Weekend } \\
\text { class time }\end{array}$ & Two times & Two times & One time & \\
$\begin{array}{l}\text { Class time } \\
\text { Kind of }\end{array}$ & $\begin{array}{l}1.5-2 \text { hours } \\
\text { rumba }\end{array}$ & $\begin{array}{l}1.5-2 \text { hours } \\
\text { Rumba, cha cha, } \\
\text { cowboy }\end{array}$ & $\begin{array}{l}\text { 2-3hours } \\
\text { Rumba, } \\
\text { cowboy, samba, } \\
\text { bullfight }\end{array}$ & cha, \\
\hline
\end{tabular}

B. Status Analysis of Junior Latin Dance Coaches in Pingxiang City

1) Male and female sex ratio of young Latin dance coaches in Pingxiang city: In Pingxiang coach of the gender and age children's Latin dance training institutions investigation and analysis, see from "Table IV" that training institutions coaches sex ratio has obvious imbalance, and $33 \%$ are men, $67 \%$ are women, the number of female coach coach number significantly higher than men.

It is well known that Latin dance is a synchronised dance, and the ratio of coaches to students should be 1:1.

To various equipped with male and female teachers with a lecture, if only one teacher teaching will affect the teaching effect and quality, will result in slower students' master technology, unable to fully complete the teaching action.

And it can be seen from table 4 that the 20-30 years old account for 47\%, 30-40 years old and over 40 years old, accounting for $40 \%$ and $13 \%$ respectively.

It is suggested that the coaches of the junior Latin dance training institution in Pingxiang city mainly focus on the youth and have less old age.

TABLE IV. The AGE AND GENDER QUESTIONNAIRE OF COACHES OF JUNIOR LATIN DANCE TRAINING INSTITUTIONS IN PINGXIANG CiTy (N = 15)

\begin{tabular}{llllll}
\hline & Age structure & & \multicolumn{3}{c}{ Gender structure } \\
\hline Age & The number of & Percentage (\%) & gender & The number of & $\begin{array}{l}\text { Percentage } \\
(\%)\end{array}$ \\
& & & & & $33 \%$ \\
20-30years old & 7 & $47 \%$ & men & 5 & $67 \%$ \\
30-40years pld & 6 & $40 \%$ & famela & 10 & --- \\
Above 40 years & 2 & $13 \%$ & --- & --- & 100.00 \\
old & 15 & 100.00 & --- & 15 & \\
A combined & 15 & factors & influencing the
\end{tabular}

2) Analysis of the professional time and educational factors influencing the development and operation of the status of junior Latin dance coaches in Pingxiang city: The time and education of the coaches are one of the important

TABLE V. Young Latin Dance CoAChes in PingXiang City AND ANALysis of ACAdemic DegReE

\begin{tabular}{lllllc}
\multicolumn{2}{c}{ Industry structure } & & & Degree structure \\
\hline $\begin{array}{l}\text { Working } \\
\text { time }\end{array}$ & The number & Percentage (\%) & Record of formal schooling & The number & $\begin{array}{l}\text { Percentage } \\
(\%)\end{array}$ \\
$1-3$ & 7 & $53 \%$ & college & 4 & $27 \%$ \\
$3-5$ & 4 & $27 \%$ & Undergraduate course & 9 & $60 \%$ \\
More than 5 years & 3 & $20 \%$ & A graduate student & 2 & 15 \\
A combined & 15 & 100.00 & --- & $13 \%$ \\
\hline
\end{tabular}

It can be seen from "TableV", Pingxiang for bachelor degree is more, the number of children's Latin dance teachers accounted for $60 \%$, is the main force of Pingxiang Latin dance coach, but visiting survey, bachelor degree in most of the teachers in the school of professional college students and recent graduates, when they face four to 14 years old children's groups, the lack of experience in teaching and teaching methods.

Institutions with abundant teaching experience and higher education levels and able to stabilize the mobility of coaches have better development and business models than those with more mobility.

\section{Analysis of Teaching Status of Junior Latin Dance in Pingxiang City}

1) Analysis of teaching content of children Latin dance in Pingxiang city: Each training institution should have a specific teaching plan, and it will be implemented in the short, medium and long term.

Latin dance is a basic action oriented project, its basic routines and patterns are composed of basic footwork, so the basic footwork is the main part in the teaching content.

TABLE VI. TABLE OF CONTENT ANALySIS OF JUNIOR LATIN DANCE IN PINGXIANG CiTY

\begin{tabular}{lllll}
\hline $\begin{array}{c}\text { The teaching } \\
\text { content }\end{array}$ & $\begin{array}{c}\text { The basic } \\
\text { footwork }\end{array}$ & $\begin{array}{c}\text { The special } \\
\text { theory of }\end{array}$ & $\begin{array}{c}\text { Music } \\
\text { rhythm }\end{array}$ & $\begin{array}{c}\text { The body } \\
\text { feeling }\end{array}$ \\
\hline $\begin{array}{l}\text { Jian and mei } \\
\text { art school }\end{array}$ & $44 \%$ & $23 \%$ & $18 \%$ & $15 \%$ \\
$\begin{array}{l}\text { Little rose art } \\
\text { school }\end{array}$ & $30 \%$ & $31 \%$ & $20 \%$ & $19 \%$ \\
$\begin{array}{l}\text { Bud art school } \\
\text { The dream art } \\
\text { school }\end{array}$ & $43 \%$ & $26 \%$ & $14 \%$ & $17 \%$ \\
\hline
\end{tabular}

It can be seen from "Table VI" coaches to have a reasonable knowledge structure and improve the system of knowledge, not only a clear understanding about the 
development of Latin origin and special technology theory, also to be able to do well in the process of teaching training methods.

Investigation of the four schools only health and beauty of the art schools and buds art schools put more emphasis on basic footwork exercises, but also only account for about $45 \%$ of the teaching content, and little rose art schools and interpreta dream school more pay attention to the special theory of teaching, can learn from these data that the teaching content of the four schools is different and has bigger difference.

Therefore, it can be concluded that there is a lack of consistency in the teaching content of junior Latin dance training institutions in Pingxiang city, and there is no reasonable standard syllabus.

Coaches in the teaching of children's should be all aspects of attention, because the coach's knowledge structure is more comprehensive, more can help children's all-round development of body and mind, education of high level talents.

2) Teaching Method of Junior Latin Dance in Pingxiang City: In the teaching of children Latin dance, the teaching method of the instructor's instruction and demonstration is in a dominant position, which directly influences the students' learning methods.

Pingxiang children's Latin dance training institutions most coaches are using traditional teaching methods, such as action demonstration, practice and complete decomposition, etc., relative to students interested in methods, such as game method, the situational teaching method in the classroom should consider children love to play with appropriate to the heart of the application.

\section{The Current Situation of Junior Latin Dance Training Institution in Pingxiang City}

1) Analysis of the status quo of the facilities of junior Latin dance training institution in Pingxiang city: Site facilities are indispensable material conditions in the process of the movement, and the quality of the facilities has a significant impact on the quality of teaching. Latin dance is a beautiful and passionate dance, and the standard venue facilities will promote students' interest in learning dance. The standard pitch of Latin dance is 50 meters wide and 25 meters wide, and the ground requires a smooth wooden floor. The classroom is surrounded by two meters of mirrors and multimedia teaching equipment. Through the survey of Pingxiang children's Latin dance training institutions, such as "Table VII", it can be seen that the investigation of the four only a school of learning is to fulfill the requirements of the standard facilities, some schools not up to par this to a certain extent, leading to students' learning enthusiasm is not high, can't fully stimulate students' interest in sex. Four to mirror can make students observe their own dance movements from different angles, and better imitate learning and correct wrong actions by mirror.

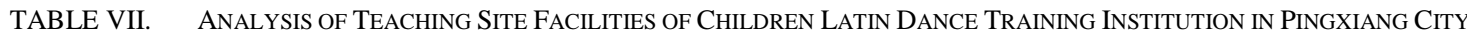

\begin{tabular}{|c|c|c|c|}
\hline School name & The standard ground & Multimedia teaching equipment & Percentage (\%) \\
\hline Jian and mei art school & & & 100 \\
\hline Bud art school & & & 50 \\
\hline The dream art school & & & 25 \\
\hline Little rose art school & & & 50 \\
\hline
\end{tabular}

2) The investigation and analysis of the charging situation of junior Latin dance training institution in Pingxiang city: Charge is the basis of the development of children's Latin dance training organization management, can see from the "Table VIII" of the four schools charge indicator is in a state of equilibrium, charging higher school is little lower school almost no, so that we can make the subsequent development of Pingxiang children's Latin dance training institutions in a relatively balanced phase.

Charge from employs only a school semester tuition fees and the situation is relative to other schools in the condition of higher, because the school is the investigation of the four schools in the opening time is long, relatively stable school, so its rate will be higher than other schools.

Yet this charging method can drive the Pingxiang children's Latin dance training institutions to the development of better, because can stimulate the development of other institutions, Pingxiang makes children's Latin dance training institution is more and more normalization and specialization.

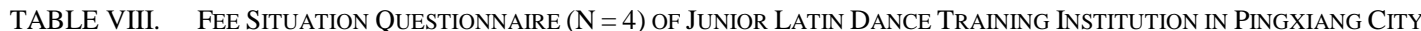

\begin{tabular}{cllllll}
\hline Project survey & Charging indicator & The number of & Percentage (\%) & Tuition fee (term) & The number of & Percentage (\%) \\
\hline Cost of distinction & 100 & 2 & 50 & $600-800$ & 2 & 50 \\
\multirow{5}{*}{ Entry fee } & 120 & 1 & 25 & --- & -- & -- \\
& 150 & 1 & 25 & $800-1000$ & 1 & 25 \\
\multirow{5}{*}{ Clothes cost } & 120 & 2 & 50 & --- & -- & -- \\
& 180 & --- & 50 & More than 1000 & 1 & 25 \\
& 240 & 2 & 50 & & & \\
\hline
\end{tabular}




\section{E. To Promote the Analysis of the Market Development of the Latin Dance Training Market in Pingxiang City}

1) Improve the site facilities and improve the quality of the facilities: Now site Pingxiang Latin dance training institutions is less, not very good to meet demand, if you want to children's Latin dance can better development, better development for this project, first to build more perfect training institutions.

2) Strengthen the training of coaches: Whether the training institution can operate in the long term has a great relationship with the professional staff.

Coaches should have long-term system training and improve themselves at the same time as teaching students, improving technical skills and reducing mobility.

3) Strengthen the publicity of training institutions: It is often not enough for training agencies to stay on leaflets and outdoor classes, as more and more people are using the Internet in recent years, especially for WeChat.

Only by increasing the means of publicity can the recruitment of students be better.

\section{CONCLUSION AND SUGGESTIONS}

\section{A. The Conclusion}

- The cognitive and learning motivation of the students of young Latin dance in Pingxiang city is largely due to the strengthening of art cultivation and shaping and learning of Latin dance through the choice of parents.

- The gender ratio of male and female Latin dancers in Pingxiang city is seriously unbalanced, and the students are mainly primary in primary school;

- The class is divided into the students' ability to learn basic movements and the level of acceptance, and divided the class into elementary, intermediate and advanced classes.

- The coaches of junior Latin dance training in Pingxiang city are mainly young and middle-aged. However, due to the lack of educational background, the technical level and teaching ability are generally low.

- Pingxiang children do not have a unified the teaching content of Latin dance training institutions also have no perfect teaching system, teaching methods of the coaches most as action demonstration, practice and complete decomposition, etc give priority to these traditional methods.

- The lack of standard venue facilities for the junior Latin dance training institution in Pingxiang city.

- There is a difference in the cost of the training institution, but it can be adapted to the local level of economic development.

\section{B. Advice}

- To promote the Latin dance and promote the Latin dance in Pingxiang children's Latin dance training institution to create a good atmosphere for the development of the Latin dance.

- Related training institutions should actively play their role, increase publicity and promotion of Latin dance, let more people participate in and enjoy this project, for the development of children's Latin market provides a good environment.

- Pingxiang children's Latin dance training institutions of the increasing of the private sector, there is no rigorous organization training institutions, lack of professional organization and management, to solve these problems, first of all, should let the government involvement, mandatory regulation, adjust training institutions chaos in the market.

- Small Latin dance training institutions of Pingxiang city should constantly improve them and improve market competitiveness.

- Children's Latin dance training institutions in an effort to improve conditions of teachers, service, management software at the same time, also should try our best to improve the hardware facilities, the formation of specialized schools, to seek greater development in the competition, make the children's Latin dance training constantly formalization.

- For children's Latin dance training institutions coaches liquidity problems such as big and less time, and make feasible measures, before the formal job issues of academic qualifications to guard a pass strictly, along with the office of the incumbent coach to carry on the contract, at least 2 years, and in a year or so to do staff complement method, prevent a substitute coaches phenomenon to renew the contract expires, if the coach liquidity is very unfavorable to the development of training institutions.

\section{REFERENCES}

[1] Chen Liangong. Development status and countermeasures of Latin dance in China [J]. Journal of guangzhou sports institute: 2001,21(2): 114-116.

[2] Ding Jing. Investigation and countermeasures of youth sports dance in lanzhou [J]. Journal of northwest normal university, 2009, (4): 7983.

[3] He Zhong, Xu Zhilin. Research on the problems of children's physical dance training in young children in northwest China [J]. Journal of wuhan institute of physical education. 2010,44(4): 80-83.

[4] Han Fei. The present situation and countermeasures of children's sports dance in guangzhou [D]. Guangzhou: guangzhou university, 2012.

[5] Ya Dahuang. Existing problems of children's sports dance in China [J]. Journal of chifeng institute, 2008, 29 (6): 211-212.

[6] Song Wenli. On the new Latin dance [J]. Journal of sports, 2002,(4).

[7] Duan Danwei, Jiang Dawei, meng zhaoxin. Research on teaching methods of children Latin dance [J]. Inner Mongolia sports technology, 2012 (03): 82-83. 
[8] Kong Xiangkui. The analysis of the influence factors of Latin dance [J]. Journal of chifeng college (natural science edition), 2013 (20): 74-75.

[9] The influence of the Latin dance training on the physical quality of children [J]. Hubei sports technology, 2000, (01).

[10] Wan Chao. Problems in training institutions of Latin dance club in shaanxi province [J]. Wisdom. 2009 (25).

[11] Wang Wentong. Discussion on primary teaching procedure of Latin dance [J]. Journal of Harbin institute of sport. 2002(03).

[12] Chen Hongjie. Analysis of teaching mode of children Latin dance in xi 'an city [J]. Shanxi youth (second half), 2013(11):198-198.

[13] Sun Linfang, Li Qinsheng. Investigation and development trend of the development of junior Latin dance in shandong province [J]. Shandong sports technology, 2014(03):119-122.

[14] Feng Beibei. A brief discussion on the teaching of children Latin dance [J]. Mass literature (theory). 2009, (02). 